\title{
中央駆集法及び一端駆集法による 漁網の色彩の効果*
}

\author{
草 下 孝也 \\ (東京大学農学部) \\ Experiments to see the Effect of colour on Nets by the Centralizing \\ Method and the Driving to One Side Method
}

Takaya KUSAKA

The author has done those experiments continously for the former report (Refference 1)) which was carried out "Centralizing method" and "Driving to one side method". (Fig. 1.)

10 Goldfish Carassius auratus of an average total length of $4.0 \mathrm{~cm}$. were liberated in a wooden tank of $150 \mathrm{~cm}$. long, $26 \mathrm{~cm}$. wide and $8 \mathrm{~cm}$. "water depth. For model nets of colours, 8 wooden frames were made to be stretched vinyle tube (dia. $1 \mathrm{~mm}$.) vertically at interval of $2.0 \mathrm{~cm}$. on each and the each frame had a colour of semi-transparent, yellow, white, green, pink, red, blue and except the 8th one which had fine white cotton thread.

The centralizing method was done with repeat of 40 times using all these 8 frames, and in all combinations of two frames each. The sum of the total values were given in Table 1. and they were applied the chi-square test of statistics as expressing in the Table.

The observed values by the driving to one side method were expressed in Table 2. and Fig. 2. and the efficiency of driving was given in Table 3. and 4. Average values of them had been examined different significance by the F-table of statistics, seeing in Table 5.

As regards driving fishes on the two experiments, the frames of blue, pink and red are obviously more effective than the other frames of white, yellow, semi-transparent and white cotton thread.

As it is existing difference between the human and fishes on the senses of sight, he had examined visible distance in the water for each colour of vinyle frame taking method of as in Fig. 3. and the result is in Table 6. and Fig. 4.

Consequently, those results and quoting the result of the underwater fencing net (Refference 2) were compared on order of effect of colours, seeing in Table 7. The orders of experiments (b) and (c) are accurate uniformity, as if the materials of model net are equal one and it had both taken method to drive fishes in. Though the (a) was done as fencing net unmoved, he had recognized few similarity between the orders of (a) and (d).

\section{ま え が き}

中央駆集法及び一端駆集法についてい既報りした如く，漁具の作用効果を魚類の行動反応から判断する方 法として，優れていることが明確になつたのて，今回は漁業技術の上で問題にされている漁網の色彩の唂果 について，この二つの方法を活用し，全く同じ方法によつて実験を行なつた。ここでは色彩の相違が鮘類の 感覚に作用し，これに反応する魚群の移動行動に差異を確認できるかどうかを追究する。 


\section{中央駆荣法による色彩の効果}

中央駆集法は Fig. 1 の如く，比較すへきき異なつた色彩の 2 個の網桃によつて，両側から焦群を中央に駆集 し，中央で網枠が合致した際に，左右の外側に通り妨たた数の割合を求め，繰返しによる数理的処理によ って，有意な差異を求めるすのである。
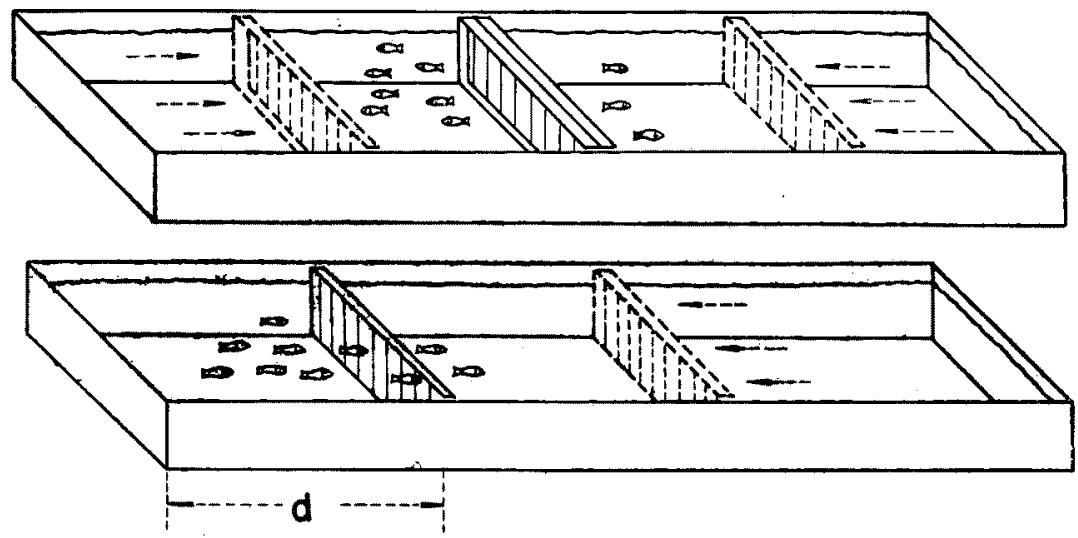

Fig. 1. Centralizing method (the above) and Driving to one side method (the below).

実駼魚はキンギョCarassius auratus 10 匹，体長 $3.5 \sim 4.5 \mathrm{~cm}$ を用い，水槽は白色ペンキ塗り木製，長 さ $150 \mathrm{~cm}$, 巾 $26 \mathrm{~cm}$, 水深 $8 \mathrm{~cm}$ である。色彩網としては木枠 $($ 巾 $25 \mathrm{~cm}$, 高さ $10 \mathrm{~cm})$ にビ二ール糸 （管状，径約 $1 \mathrm{~mm}$ )を $2 \mathrm{~cm}$ 間隔に縱に張つたすので, その種類としてはビニール系の半透明無色, 白, 黄, 緑，青，桃色，赤及び比較の為，無染色綿撚系を張つたるのを加えて 8 種類を用意した。これから，2 種類 ずつ選んだ総べての組合せについて,各々40 回絽返しを行なつて,左右の側に通り外た魚体の数を記録し 合計した。(Table 1) これらの観測值について，カイ自乗検定を行なつた。起りらる確率を5\%以内にとれ

Table 1. Effects of different colours using different combination by the centralizing method

\begin{tabular}{|c|c|c|c|c|c|c|c|c|}
\hline $\begin{array}{l}\text { Kind of } \\
\text { frames }\end{array}$ & $\begin{array}{l}\text { Semi- } \\
\text { transpa- } \\
\text { rent }\end{array}$ & Yellow & White & $\begin{array}{l}\text { white } \\
\text { cotton } \\
\text { thread }\end{array}$ & Green & Pink & Blue & Red \\
\hline $\begin{array}{l}\text { Semi- } \\
\text { transpa- } \\
\text { rent }\end{array}$ & & $\begin{array}{l}182 \\
218\end{array}$ & $\begin{array}{l}193 \\
207\end{array}$ & $\begin{array}{l}210 \\
190\end{array}$ & $\begin{array}{l}193 \\
207\end{array}$ & $\begin{array}{l}160 \\
240\end{array}$ & $\begin{array}{l}183 \\
217\end{array}$ & $\begin{array}{l}165 \\
235\end{array}$ \\
\hline Yellow & $10 \%$ & & $\begin{array}{l}202 \\
198 \\
\end{array}$ & $\begin{array}{l}203 \\
197 \\
\end{array}$ & $\begin{array}{l}201 \\
199\end{array}$ & $\begin{array}{l}165 \\
235\end{array}$ & $\begin{array}{l}171 \\
229\end{array}$ & $\begin{array}{l}172 \\
228 \\
\end{array}$ \\
\hline White & - & - & & $\begin{array}{l}186 \\
214 \\
\end{array}$ & $\begin{array}{l}197 \\
203 \\
\end{array}$ & $\begin{array}{l}187 \\
213 \\
\end{array}$ & $\begin{array}{l}151 \\
249 \\
\end{array}$ & $\begin{array}{l}173 \\
227 \\
\end{array}$ \\
\hline $\begin{array}{l}\text { White } \\
\text { cotton } \\
\text { thread }\end{array}$ & - & 一 & - & & $\begin{array}{l}202 \\
198\end{array}$ & $\begin{array}{l}182 \\
218\end{array}$ & $\begin{array}{l}165 \\
235\end{array}$ & $\begin{array}{l}168 \\
232\end{array}$ \\
\hline Green & - & - & - & - & & $\begin{array}{l}184 \\
216\end{array}$ & $\begin{array}{l}190 \\
210\end{array}$ & $\begin{array}{l}182 \\
218\end{array}$ \\
\hline Pink & 1 & 1 & - & 10 & - & & $\begin{array}{l}196 \\
204\end{array}$ & $\begin{array}{l}195 \\
205\end{array}$ \\
\hline Blue & 10 & 1 & 1 & 1 & - & - & & $\begin{array}{l}197 \\
203\end{array}$ \\
\hline Red & 1 & 1 & 1 & 1 & 10 & - & - & \\
\hline
\end{tabular}

The right upper figure : Sum of values for forty experiment, of the fish moved to either side.

The left lower figure : Level of significance $(\%)$ of the chi-spuare test. 


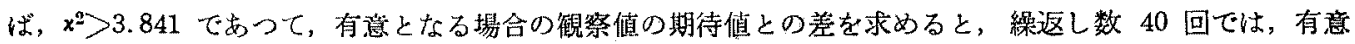

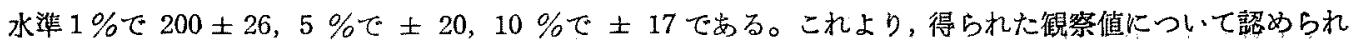
る有意水準を Table 1 に示した。尚，此校のために同種のビニール網枠の共に半透明無色のるので,得られ た観察值は $205 ： 195$ で有意差は全くみられないるのであつた。

これらの結果によれば色彩の效果の差巽が相当な信頼性をもつて示された。全般的には阻止効果の多い組, 即ち，赤，青，桃色と少ない組，綿系，白，雰，半湮明とに犼けてみることができる。

\section{一端駆菓法による色彩の効果}

この方法は水槽の一端より網枠で魚群を他端に追い，魚が網枠を通りぬけて，(ここでは 10 個体の3匹

Table 2. The distances in $\mathrm{cm}$. from the frame position of passage of fish to the side of tank in the driving to one side method

\begin{tabular}{|c|c|c|c|c|c|c|c|c|c|c|c|c|c|c|c|c|c|c|}
\hline \multirow{3}{*}{$\frac{{ }_{\text {Repe- }}^{\text {at }}}{}$} & \multicolumn{9}{|c|}{ Kind of frames } & \multirow[b]{2}{*}{$\begin{array}{l}\text { Repe } \\
\text { at }\end{array}$} & \multicolumn{8}{|c|}{ Kind of fremes } \\
\hline & $\begin{array}{l}\text { Whi- } \\
\text { te co- } \\
\text { tton } \\
\text { thre- } \\
\text { ad }\end{array}$ & $\begin{array}{l}\text { Semi- } \\
\text { trans } \\
\text { pare- } \\
\text { nt }\end{array}$ & $\begin{array}{l}\text { Yel- } \\
\text { low }\end{array}$ & $\begin{array}{l}\text { Whi } \\
\text { te }\end{array}$ & $\begin{array}{c}\text { Gro } \\
\text { en }\end{array}$ & & Pink & Red & Blue & & $\begin{array}{l}\text { Whi- } \\
\text { te co- } \\
\text { tton } \\
\text { thre- } \\
\text { ad }\end{array}$ & \begin{tabular}{|l} 
Semi- \\
trans- \\
pare- \\
nt
\end{tabular} & $\begin{array}{l}\text { Yel- } \\
\text { low }\end{array}$ & $\begin{array}{l}\text { Whi- } \\
\text { te }\end{array}$ & $\begin{array}{l}\text { Gre- } \\
\text { ne }\end{array}$ & Pink & Red & Blue \\
\hline & 21 & 48 & 41 & 21 & & 26 & 8 & 19 & 18 & 21 & 26 & 16 & 15 & 14 & 12 & 29 & 10 & 9 \\
\hline 2 & 15 & 48 & 11 & 12 & & 14 & 11 & 12 & 8 & 22 & 13 & 12 & 13 & 12 & 11 & 17 & 12 & 13 \\
\hline 3 & 20 & 12 & 26 & 52 & & 32 & 7 & 13 & 24 & 23 & 18 & 8 & 11 & 7 & 5 & 7 & 5 & 7 \\
\hline 4 & 6 & 41 & 42 & 43 & & 36 & 45 & 12 & 27 & 24 & 16 & 14 & 15 & 13 & 6 & 10 & 8 & 7 \\
\hline 5 & 48 & 14 & 23 & 18 & & 9 & 18 & 9 & 27 & 25 & 19 & 20 & 27 & 45 & 18 & 18 & 16 & 12 \\
\hline 6 & 38 & 14 & 7 & 24 & & 8 & 33 & 15 & 16 & 26 & 8 & 6 & 10 & 18 & 6 & 19 & 14 & 7 \\
\hline 7 & 7 & 20 & 15 & 11 & & 10 & 11 & 10 & 15 & 27 & 9 & 22 & 26 & 48 & 13 & 6 & 14 & 6 \\
\hline 8 & 10 & 8 & 14 & 15 & & 13 & 10 & 15 & 14 & 28 & 11 & 16 & 6 & 37 & 11 & 7 & 20 & 6 \\
\hline 9 & 20 & 12 & 7 & 12 & & 30 & 5 & 6 & 7 & 29 & 42 & 13 & 16 & 9 & 7 & 5 & 7 & 5 \\
\hline 10 & 34 & 20 & 8 & 6 & & 7 & 7 & 6 & 11 & 30 & 6 & 17 & 12 & 10 & 10 & 9 & 8 & 7 \\
\hline 11 & 20 & 8 & 40 & 25 & & 7 & 18 & 6 & 8 & 31 & 12 & 10 & 13 & 23 & 15 & 10 & 17 & 8 \\
\hline 12 & 7 & 21 & 10 & 11 & & 22 & 6 & 17 & 7 & 32 & 11 & 8 & 13 & 11 & 30 & 11 & 6 & 10 \\
\hline 13 & 6 & 65 & 21 & 13 & & 8 & 13 & 8 & 11 & 33 & 15 & 11 & 35 & 23 & 10 & 9 & 5 & 14 \\
\hline 14 & 18 & 16 & 13 & 15 & & 13 & 12 & 7 & 10 & 34 & 21 & 10 & 12 & 16 & 14 & 6 & 7 & 7 \\
\hline 15 & 16 & 12 & 10 & 23 & & 11 & 6 & 8 & 12 & 35 & 17 & 7 & 15 & 9 & 10 & 10 & 8 & 15 \\
\hline 16 & 9 & 12 & 13 & 39 & & 9 & 7 & 11 & 11 & 36 & 11 & 15 & 14 & 11 & 12 & 10 & 8 & 8 \\
\hline 17 & 8 & 8 & 40 & 13 & & 9 & 7 & 10 & 15 & 37 & 9 & 9 & 13 & 8 & 10 & 8 & 9 & 8 \\
\hline 18 & 21 & 16 & 27 & 9 & 1 & 18 & 8 & 16 & 16 & 38 & 10 & 10 & 11 & 14 & 10 & 9 & 10 & 11 \\
\hline 19 & 14 & 23 & 44 & $1 \hbar$ & & 14 & 6 & 10 & 9 & 39 & 11 & 13 & 9 & 10 & 10 & 11 & 9 & 8 \\
\hline 20 & 15 & 7 & 20 & 36 & & 20 & 30 & 9 & 20 & 40 & 9 & 13 & 10 & 30 & 24 & 11 & 10 & 6 \\
\hline
\end{tabular}

Table 3. Percentages of numbers for 40 times, to drive fish in some range by each frame used

\begin{tabular}{|c|c|c|c|c|c|c|c|c|c|}
\hline \multirow{2}{*}{\multicolumn{2}{|c|}{$\begin{array}{l}\text { Distance from } \\
\text { the position } \\
\text { of frame to } \\
\text { the side of tank }\end{array}$}} & \multicolumn{8}{|c|}{ Kind of frames } \\
\hline & & White & Yellow & $\begin{array}{l}\text { Semi- } \\
\text { trans- } \\
\text { parent }\end{array}$ & $\begin{array}{l}\text { White } \\
\text { cotton } \\
\text { thread }\end{array}$ & Green & Blue & Pink & Red \\
\hline Below & $10 \mathrm{~cm}$ & $32.5 \%$ & 35 & 45 & 45 & 57.5 & 67.5 & 75 & 72.5 \\
\hline "I & 15 & 60 & 67.5 & 75 & 65 & 75 & 87.5 & 80 & 95 \\
\hline$" \prime$ & 20 & 67.5 & 72.5 & 87.5 & 87.5 & 85 & 92.5 & 90 & 100 \\
\hline "I & 30 & 82.5 & 85 & 90 & 90 & 97.5 & 100 & 95 & - \\
\hline$" \prime$ & 40 & 90 & 97.5 & 92.5 & 97.5 & 100 & - & 97.5 & - \\
\hline$\prime \prime$ & 60 & 100 & 100 & 97.5 & 100 & - & - & 100 & - \\
\hline
\end{tabular}


目の通過を観測した)。他の側へのがれる時の網枠の 位管を記録する方法である。(Fig. 1)実駼材料はすべ て前章と同じすので,各々の網枠について，40回繰返 した観察結果は Table 2 の如くであるこれらにつ いて，各網执ごとに 40 回繰返しの頻度分布を求め ると Fig.2．の如くで，図形によつて，各色彩の効 果を比較判断することができる。又，結果から，水 槽の或る位置まで，追い集め得た度数の100分率を 出してみると Table 3 の如くである。更に䋩祭值の 分布が偏在しているので，個々の観察值を刘数にな 扣して，各色彩に括ける平均値攻び標準偏差を求め て, 駆集效果の順位を Table 4 に示した。これに よると駆集効果の少ない色彩のもので，大体無染色 綿糸々同程度であり，就果の上いもの，即ち，赤， 桃色，青の網枠（間隔 $2.0 \mathrm{~cm}$ ）では前報に怙ける 綿系間隔 $1.5 \sim 1.0 \mathrm{~cm}$ のすのに匹敵している。こ れからして，駆集する網では色彩によつて刻果にか なり相違があることが立証された。次に各色彩間の 平均駆集度について，并の差の有意性を検討した。 Table 5 の如く, 組合せの約半数に有意差が認めら

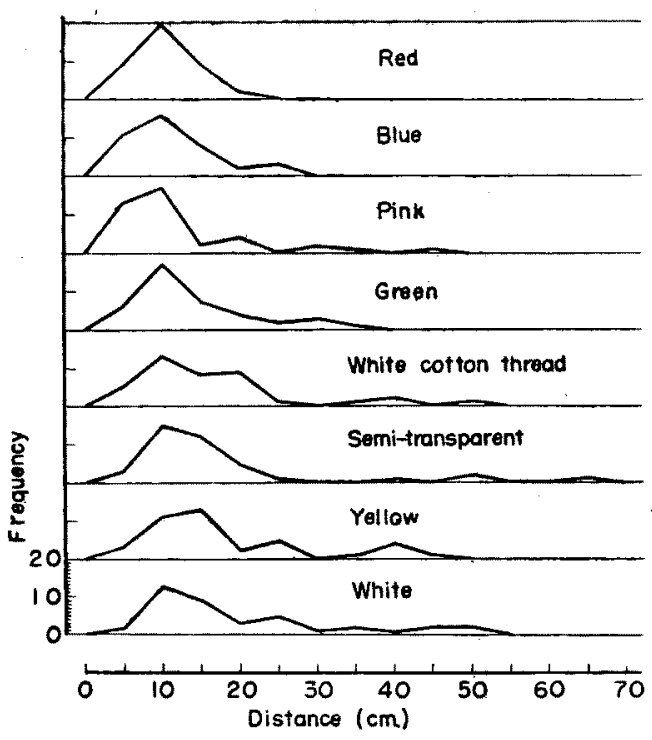

Fig. 2 Frequency distributions of 40 times for the effects of each frame by the driving to one side method.

Table 4. Mean values of driving efficiency by the driving to one side method

\begin{tabular}{l|c|c|c|c|c|c|c|c}
\hline$\quad$ Kind of frames & $\begin{array}{c}\text { White } \\
\text { cotton } \\
\text { thread }\end{array}$ & $\begin{array}{l}\text { Semi- } \\
\text { trans- } \\
\text { parent }\end{array}$ & Yellow & White & Green & Pink & Red & Blue \\
\hline Repeated for 40 times & 1.141 & 1.147 & 1.191 & 1.213 & 1.087 & 1.013 & 0.989 & 1.014 \\
\hline $\begin{array}{l}\text { Sum of measured values which } \\
\text { vere converted to common lo- } \\
\text { garithm }\end{array}$ & 45.65 & 45.81 & 47.65 & 48.53 & 43.50 & 40.54 & 39.59 & 40.57 \\
$\begin{array}{l}\text { Mean of the measured values } \\
\text { Standard deviation for the mean }\end{array}$ & \pm 0.232 & \pm 0.239 & \pm 0.234 & \pm 0.247 & \pm 0.214 & \pm 0.232 & \pm 0.161 & \pm 0.189 \\
\hline $\begin{array}{l}\text { Averages which were reconver } \\
\text { ted from the mean (cm.) }\end{array}$ & 13.84 & 14.03 & 15.53 & 16.34 & 12.22 & 10.31 & 9.75 & 10.33 \\
\hline \begin{tabular}{l} 
Order of driving efficiency \\
\hline
\end{tabular} & $(5)$ & $(6)$ & $(7)$ & $(8)$ & $(4)$ & $(2)$ & $(1)$ & $(3)$ \\
\hline
\end{tabular}

れた。このように阻止効果について, 緑は中間的でめるが, 青, 桃色, 赤の一群之白, 黄, 半透明, 綿糸の 群との間には明確な有意差が得られた。

\section{色彩ビニール網枠の水中可視距離}

こ机は我々の肉眼で見た色彩感からであるが，8種類の色彩ビニ一ルの網枠が水中でどのように認識でき るが調べた。Fig. 3 の如く，実験水槽中で，鏡を用いて水中可視距離を測定した。水槽の状沉は本実験の 観祭を行なつたままて，水は此較的濁つた状況で，9 月 4 日 12 時, 雯, 水温 $23.5^{\circ} \mathrm{C}$ に行なつた。その結 果は Table 6 及び Fig. 4 の如く，上り遠方で裙め5 る順位虫黄, 青, 白, 桃色, 赤, 綿糸, 緑, 半唀明の 順で，前述の二つの駆集法による色彩㸚果との間には 関眑を認め難い。

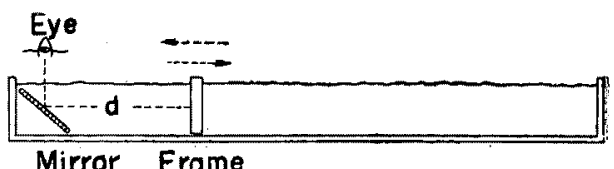

Fig. 3 Setting by eye observation of visible distances in the water for the frames. 
Table 5. Test of significant difference between mean values of driving efficiency for 40 times by the driving to one. side method

\begin{tabular}{|c|c|c|c|c|c|c|c|c|}
\hline $\begin{array}{l}\text { Kind of } \\
\text { frames }\end{array}$ & White & Yellow & $\begin{array}{l}\text { Semi- } \\
\text { trans- } \\
\text { parent }\end{array}$ & $\begin{array}{l}\text { White } \\
\text { cotton } \\
\text { thread }\end{array}$ & Green & Blue & Pink & Red \\
\hline White & & $\begin{array}{l}0.022 \\
0.241\end{array}$ & $\begin{array}{l}0.066 \\
0.243\end{array}$ & $\begin{array}{l}0.072 \\
0.240\end{array}$ & $\begin{array}{l}0.126 \\
0.231\end{array}$ & $\begin{array}{l}0.199 \\
0.220\end{array}$ & $\begin{array}{l}0.200 \\
0.242\end{array}$ & $\begin{array}{l}0.224 \\
0.208\end{array}$ \\
\hline Yellow & - & & $\begin{array}{l}0,044 \\
0.237\end{array}$ & $\begin{array}{l}0.050 \\
0.233\end{array}$ & $\begin{array}{l}0.104 \\
0.224\end{array}$ & $\begin{array}{l}0.177 \\
0.213\end{array}$ & $\begin{array}{l}0.178 \\
0.233\end{array}$ & $\begin{array}{l}0.202 \\
0.202\end{array}$ \\
\hline $\begin{array}{l}\text { Semi- } \\
\text { trans- } \\
\text { parent }\end{array}$ & - & - & & $\begin{array}{l}0.006 \\
0.236\end{array}$ & $\begin{array}{l}0.060 \\
0.227\end{array}$ & $\begin{array}{l}0.133 \\
0.216\end{array}$ & $\begin{array}{l}0.134 \\
0.236\end{array}$ & $\begin{array}{l}0.158 \\
0.105\end{array}$ \\
\hline $\begin{array}{l}\text { White } \\
\text { cotton } \\
\text { thread }\end{array}$ & - & - & - & & $\begin{array}{l}0.054 \\
0.223\end{array}$ & $\begin{array}{l}0.127 \\
0.212\end{array}$ & $\begin{array}{l}0.128 \\
0.232\end{array}$ & $\begin{array}{l}0.152 \\
0.201\end{array}$ \\
\hline Green & $5 \%$ & 5 & - & - & & $\begin{array}{l}0.073 \\
0.202\end{array}$ & $\begin{array}{l}0.074 \\
0.223 \\
\end{array}$ & $\begin{array}{l}0.0 \$ 8 \\
0.191 \\
\end{array}$ \\
\hline Blue & 1 & 1 & 1 & 1 & - & & $\begin{array}{l}0.001 \\
0.212\end{array}$ & $\begin{array}{l}0.025 \\
0.176\end{array}$ \\
\hline Pink & 1 & 1 & 5 & 5 & - & - & & $\begin{array}{l}0.024 \\
0.201 \\
\end{array}$ \\
\hline Red & 1 & 1 & 1 & 1 & 5 & - & - & \\
\hline
\end{tabular}

The right upper figure:

The above : Difference between mean values of two frames combined.

The below : Common standard deviation for the pair.

The left lower figure: Level of significance $(\%)$.

Table 6. Visible distances in $\mathrm{cm}$. in the water for the frames

\begin{tabular}{c|c|c|c|c|c|c|c|c|c}
\hline Repeat & $\begin{array}{c}\text { Kind of frames } \\
\text { cotton } \\
\text { thread }\end{array}$ & $\begin{array}{l}\text { Semi- } \\
\text { trans- } \\
\text { parent }\end{array}$ & Pink & White & Red & Blue & Yellow & Green \\
\hline 1 & $45 \mathrm{~cm}$ & 40 & 54 & 54 & 47 & 57 & 55 & 44 \\
2 & 43 & 41 & 49 & 54 & 46 & 56 & 60 & 43 \\
3 & 43 & 38 & 51 & 55 & 50 & 58 & 61 & 42 \\
\hline Mean values & 44 & 40 & 51 & 54 & 48 & 57 & 59 & 43 \\
\hline Order of visible distances & $(6)$ & $(8)$ & $(4)$ & $(3)$ & $(5)$ & $(2)$ & $(1)$ & $(7)$ \\
\hline
\end{tabular}

\section{駆集する絧の色彩効果の検討}

中央駆集法と一端駆集法とによる色彩効果は両者か ら，砝ど同様な結果が得られ，色彩の阻止効果が予期 以上に明確になつだ。

即ち, 効果に差異の證められる色彩群は青, 桃色, 赤の組て駆策效果がよく，白，䔮，半透明，綿糸の組 ては就果が少なく、これらの前者は臽調の触明なるの であり，後者は包の淡い不転明なものと見ることがで きる。

更に色彩効果について，色彩沈垣網 $\left.{ }^{2}\right)$ の結果とも合 せて検討する為に，これらから得られた刘果の程度を 大，小，同等の記号で配灌し，全般的な関係をみた。 Table 7 の如く，これについて判断してみると（a) と (b) (c) とではエナメル板とビニール糸と材料が 異なつているので，色彩のみについて一概に枝べられ

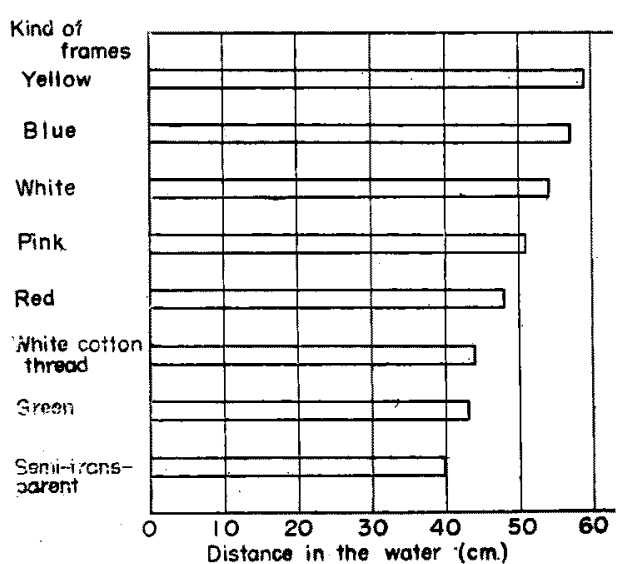

Fig. 4. Visible distances in $\mathrm{cm}$. in the water for the model nets. 
Table 7. Comparison on effects of colours among four experiments

(a) Stopping effects by tin plates enamel coloured as fencing net : White $=$ Blue $\gg$ Yellow $>$ Red $\gg$ Black

(b) Driving effects of coloured vinyle frames by the centralizing method : Red $\geqq B l u e \geq$ Pink> Green

$\gg$ White $\geqq$ White cotton thread $\geqq$ Yellow $>$ Semi-transparent

(c) Driving effects of coloured vinyle frames by the driving to one side method : Red >Pink $\geqq$ Blue $>$ Green $>$ White cotton thread $\geqq$ Semi transparent $>$ Yellow $>$ White

(d) Order so far visible distances in the water of coloured vinyle frames: Yellow>Blue $>$ White $>$ Pink $>$ Red $>$ White cotton thread $>$ Green $>$ Semi transparent

ないが（a）は供試物が設監されて動かない場合であり，(b)（c）は供試物が移動して魚群を駆集している 場合であるのて，両者の色彩効果の順位が不同なのではいかと思われる。筆者は物体が動くか、動かない かは魚類に対して，その反㤁に大きな相違があるすのと考えている。

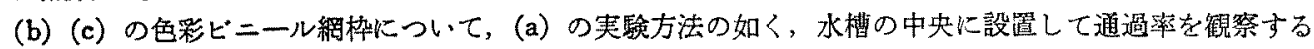
方法を施行すれい゙，上記の点について検討できるわけであるが，予備的に行なつた実験では観察が困難で記 録し得なかつた。これは色彩エナメル板と異つて，木枠に細いビニール糸を張つたのみでめるために，剌戟 が弱いことによると思われる。(d) の水中可視距離の順位は（b）(c) の順位とは殆んど無関係と見られる が，(a）の沈亘網の場合とは多少関保があるように思われる。即ち，より遠方から認識さ礼る色彩において は魚群の通過が低下するという関係は考えうることである。一方，魚群を追つて移動してくる物体に対して は，先天的に或る色彩をひどく怖れるということが魚類の感覚にあつてよいと考えられ（b) (c) の結果か

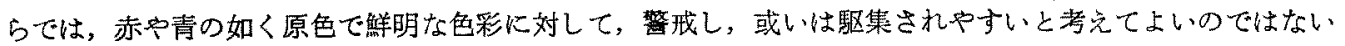
かと考光る。

魚類に及は色彩効果は非常に微妙であるが，又，强い刺戟を与える場合る多く，これらに関して，更に 多面的に考究をすべきである。

本報告の終りにのぞみ，終始，御指筫を賜つた東大教授檜山義夫博士に深謝する次第である。

女献

1）草下孝也：駆集網に関する二つの㬰験方法による網目の大きさ，本誌，22（11），(1957）

2）檜山封夫，草下孝也，近藤主吉：彩色した沈垣網の効果について，本誌，22（10，（1957） 